\title{
The Cholinergic and
}

\section{ACE-2-Dependent Anti-Inflammatory Systems in the Lung: New Scenarios Emerging From COVID-19}

\author{
Martina Di Maro'1†, Mauro Cataldi2†, Mariarosaria Santillo', Martina Chiurazzi' \\ Simona Damiano ${ }^{1 *}$, Barbara De Conno ${ }^{1}$, Antonio Colantuoni ${ }^{1}$ and Bruna Guida \\ 1 Department of Clinical Medicine and Surgery, Physiology Nutrition Unit, University of Naples Federico II, Naples, Italy, \\ ${ }^{2}$ Department of Neuroscience, Reproductive Sciences and Dentistry, Division of Pharmacology, University of Naples \\ Federico II, Naples, Italy
}

The renin angiotensin system and the cholinergic anti-inflammatory pathway have been recently shown to modulate lung inflammation in patients with COVID-19. We will show

OPEN ACCESS

Edited by:

Maria Elena Soto,

Instituto Nacional de Cardiologia

Ignacio Chavez, Mexico

Reviewed by:

Ibrahim Fadil Benter,

Eastern Mediterranean University,

Turkey

Marcelo N. Muscará,

University of São Paulo, Brazil

*Correspondence:

Simona Damiano

simona.damiano@unina.it

tThese authors have contributed equally to this work and share first authorship

Specialty section:

This article was submitted to Integrative Physiology,

a section of the journal

Frontiers in Physiology

Received: 15 January 2021

Accepted: 19 April 2021

Published: 13 May 2021

Citation:

Di Maro M, Cataldi M, Santillo M Chiurazzi M, Damiano S, De Conno B, Colantuoni A and Guida B (2021) The

Cholinergic and ACE-2-Dependent Anti-Inflammatory Systems in the Lung: New Scenarios Emerging From COVID-19.

Front. Physiol. 12:653985. doi: 10.3389/fphys.2021.653985 how studies performed on this disease are starting to provide evidence that these two anti-inflammatory systems may functionally interact with each other, a mechanism that could have a more general physiological relevance than only COVID-19 infection.

Keywords: severe acute respiratory syndrome coronavirus 2, lung, inflammation, nicotinic acetylcholine receptors, angiotensin-converting enzyme 2

\section{INTRODUCTION}

Two anti-inflammatory systems have primary role in controlling inflammation in the lung. The first is based on cholinergic neurotransmission and neuronal-type nicotinic acetylcholine receptors (nAChR) which are nowadays emerging as important players, not only in lung inflammation but also in lung carcinogenesis. The other system is centered on small peptides generated by the ReninAngiotensin System (RAS) whose role in the control of arterial blood pressure is well known, but recently emerged as important mediators of inflammation not only in the lung but also in other organs, such as the kidney or the cardiovascular system. Recent investigations on the pathogenetic mechanisms of the ongoing devastating COVID-19 pandemic suggest that the cholinergic antiinflammatory system and the RAS system could converge at some point in the pathways inducing lung inflammation. Understanding such a convergence could help to disentangle the intricate relationship between tobacco smoking and the risk of COVID-19, facilitating new therapeutic approaches for this disease and unveiling more general issues on the regulation of inflammation in lung diseases.

\section{THE CHOLINERGIC ANTI-INFLAMMATORY SYSTEM IN PULMONARY INFLAMMATION}

Neuronal type nAChR are pentameric receptor-operated cationic channels constituted by the homomeric or heteromeric assembly of nine different isoforms of $\alpha$, and three different isoforms

Abbreviations: ACE, Angiotensin-converting enzyme; ACE-2, Angiotensin-converting enzyme 2; Ach, Acetylcholine; Ang II, Angiotensin II; Ang-(1-7), Angiotensin-(1-7); Ang-(1-9), Angiotensin-(1-9); AT1-R, Angiotensin II receptor type 1; AT2R, Angiotensin II receptor type II; COPD, chronic obstructive pulmonary disease; COVID-19, coronavirus disease 2019; Ko, knockout; Mas-R, Mas-receptor; nAChR, nicotinic acetylcholine receptors; RAS, Renin-angiotensin system; SARS-CoV2, severe acute respiratory syndrome coronavirus 2 . 
of $\beta$ subunits (Yamada and Ichinose, 2018). Among these different subunits the expression of $\alpha 3, \alpha 4, \alpha 5, \alpha 7, \beta 2$, and $\beta 4$ has been demonstrated in the lung (Lippi and Henry, 2020), where they form nAChR that can be activated either by the Ach directly synthetized by epithelial lung cells (Kuba et al., 2005) or by the Ach released from vagal terminals that innervate also distal airways (Fox et al., 1980). In recent years attention has been focused on homomeric $\alpha 7$ receptors (Hajiasgharzadeh et al., 2019). These rapidly desensitizing, highly $\mathrm{Ca}^{+}$permeable nAChRs, with the unusual property of responding not only to Ach but also to choline, were first identified in the lung by Wang et al. (2001) who demonstrated their presence in human bronchial epithelial cells. Hollenhorst et al. (2012) demonstrated that nicotine binding to nAchR is effective in activation of transepithelial ion transport in mouse tracheal epithelium involving adenylyl cyclase activity. Kumar et al. (2020) studied many subtypes of nAChRs, such as $\alpha 3 \beta 4$, able to increase $\mathrm{Ca}^{2+}$ release from intracellular store in the mouse trachea. Studies in $\alpha 7 \mathrm{nAChR}$ ko mice, showing enhanced tissue inflammation in response to different inflammogens, support the hypothesis that these receptors could negatively modulate the inflammatory response ( $\mathrm{Su}$ et al., 2010). The cholinergic regulation of macrophage function through $\mathrm{nAChR} \alpha 7$ is part of the wider cholinergic anti-inflammatory pathway operated by vagal nerves in the modulation of tissue inflammation (MacKenzie, 2011). In this contest, an anti-inflammatory effect was observed in the lung where it could represent an interesting target for the treatment of both acute and chronic inflammatory diseases (Su et al., 2010; Brégeon et al., 2011; Yamada and Ichinose, 2018). Recent studies indicate that protection from inhaled pathogens evolved in the airways through mucociliary clearance and cough. The protective respiratory reflexes to locally released bacterial bitter "taste" substances are most probably initiated by tracheal brush cells (BC), able to synthetize Ach, effective in stimulating $\mathrm{nAChR}$, and several other intracellular signal molecules (Hollenhorst et al., 2020). In particular, nicotinic stimulation of $\alpha 3 \beta 4-\mathrm{nAChR}$ acutely increases particle transport speed (PTS) on the mucosal surface to the same extent as the established strong activator ATP (Perniss et al., 2020). Krasteva et al. (2011) identified cholinergic chemosensory cells in mouse trachea, able to release Ach and reduce the breathing frequency. These brush cells, as cholinergic sensors of the chemical composition of the lower airway luminal microenvironment, are directly linked to the regulation of respiration and to the immune system modulation. Khani et al. (2020) highlighted the key role played by nicotinic agonists against cytokine storm induced by COVID-19.

\section{THE RAS SYSTEM IN PULMONARY INFLAMMATION}

It has been well known that RAS participates not only to the regulation of arterial blood pressure but also in tissue inflammation. By acting on AT1 receptors (Kummer et al., 2008), Angiotensin II (Ang II), indeed, induces free radical generation, activates dendritic cells, stimulates synthesis and release of proinflammatory and chemoattractant cytokines, promotes the expression of endothelial adhesion molecules and leukocyte margination and migration in tissues (Benigni et al., 2010). Similar effects have been demonstrated also in the lung where Ang II promotes free oxygen radical formation (Wang et al., 2017), enhances vascular permeability and edema formation (Zhang and Sun, 2005), and contributes to tissue damage and remodeling by promoting the apoptosis of alveolar epithelial cells (Wang et al., 1999) and the proliferation of fibroblasts (Marshall et al., 2000). Ang II proinflammatory effects are homeostatically counteracted by another RAS peptide, Angiotensin (1-7) [Ang(1-7)] that is generated by the alternative metabolism of Ang I or Ang II by ACE2 (Silva and Teixeira, 2016), an 805 amino acids transmembrane metallopeptidase, cloned 20 years ago by Tipnis et al. (2000). More specifically, this enzyme removes a single residue from Ang II to generate Ang-(1-7) and a single residue from Ang I to yield Ang-(1-9) which is further processed to generate Ang-(1-7) (Donoghue et al., 2000). Acting on AT2 receptors and Mas receptors, Ang-(1-7) counteracts Ang II activity by inducing anti-proliferative, anti-inflammatory and antifibrotic effects as it has been demonstrated in animal models of several inflammatory disorders including rheumatoid arthritis, diabetic nephropathy, hepatic fibrosis and lung diseases such as asthma, pulmonary fibrosis and the respiratory distress syndrome (Benter et al., 2008; El-Hashim et al., 2012; Galvão et al., 2019; Magalhães et al., 2019). Interestingly, beneficial effects, probably dependent from increased Ang-(1-7) generation have been demonstrated in piglets with lipopolysaccharide-induced lung injury upon treatment with recombinant ACE-2 (Treml et al., 2010): this enzyme has also been tested in a pilot trials in humans with ARDS (Khan et al., 2017).

A new role for ACE2 in pulmonary diseases has been demonstrated by studies on two new human coronaviruses, SARS-CoV and SARS-CoV2. SARS-CoV causes the SARS epidemics that determined about 8400 cases and more than 800 deaths in 2003/2004 (Staats et al., 2020). SARS-CoV2 is responsible for the ongoing COVID-19 pandemic that at the time of writing already caused 8.52 million of cases and more than 450.000 deaths in the World (World Health Organization (WHO), 2020). Both these viruses enter target cells in the airways and diffuse into susceptible organs, such as the brain, upon binding of their surface spike protein $(S)$ to plasma membrane ACE2. More specifically, after binding to ACE 2 the S protein is cleaved by the Transmembrane Serine Protease 2 (TMPRSS2); its carboxy-terminal S2 domain is released, facilitating the fusion of viral membrane with the plasma membrane of the target cell (Hoffmann et al., 2020). ACE2 has a crucial role in the pathophysiology of SARS-CoV and SARS-CoV2 infections, as the key factor for virus penetration; however, it also participates to the pathophysiological mechanisms of these diseases in a way related to its physiological activity in the RAS modulation. It has been suggested, indeed, that ACE2 activity could by impaired after $S$ protein binding, with consequent imbalance of the RAS mechanisms, facilitating the proinflammatory activities of Ang II. Upon exposure to a fusion protein of the SARS-CoV S protein and the immunoglobulin Fc fragment, Su et al. (2010) showed that the surface density of ACE2 is significantly lowered both 


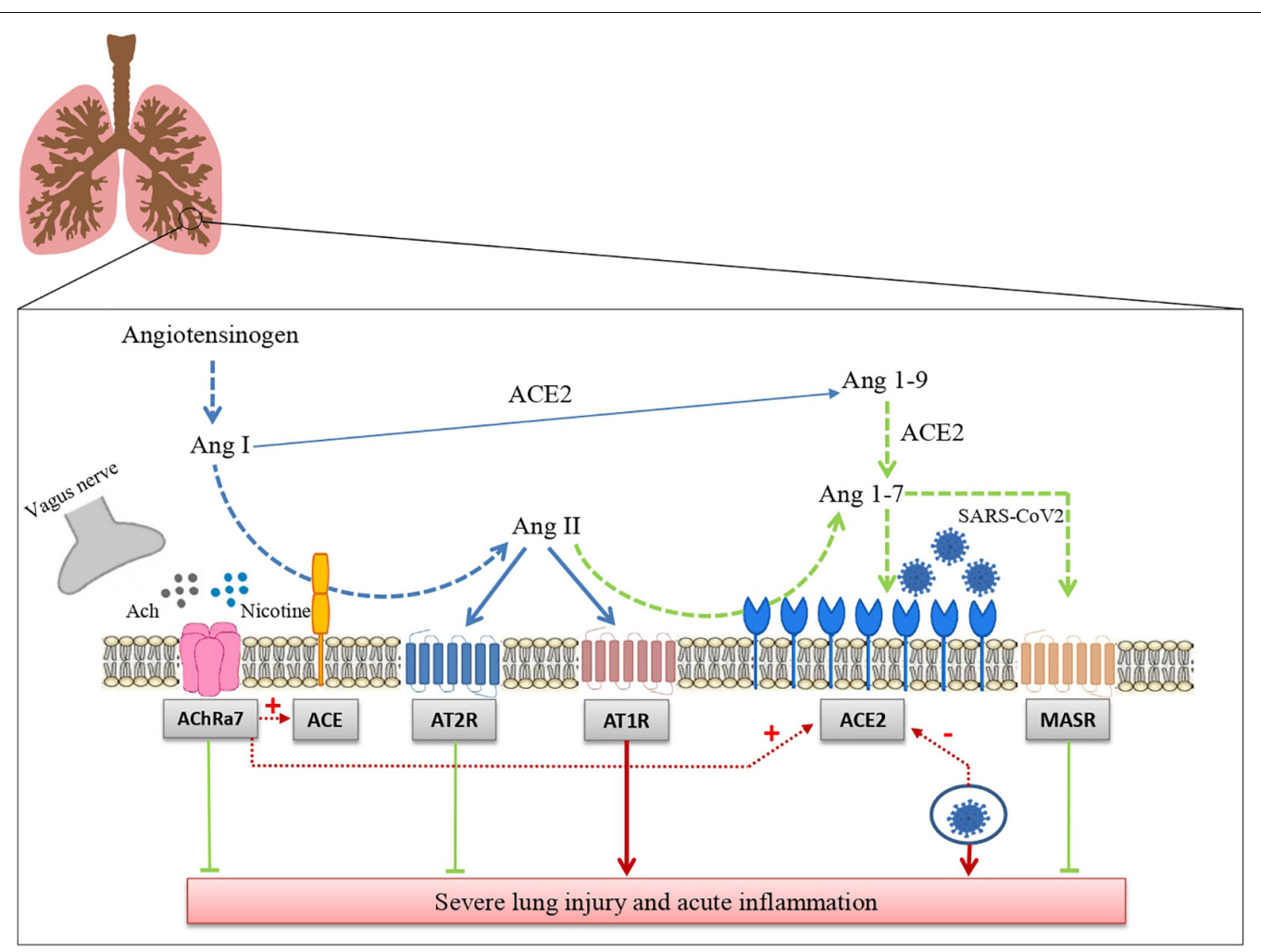

FIGURE 1 | Interaction between the renin angiotensin system and the cholinergic anti-inflammatory pathway in SARS-CoV-2 lung infection. The drawing shows how the renin angiotensin system and the cholinergic anti-inflammatory pathway modulate tissue inflammation in lungs infected with SARS-CoV-2 and how these two systems interact with each other (see the text for further details). Ang I: Angiotensin I; Ang II: angiotensin II; Ang-(1-7): angiotensin 1-7; Ang-(1-9): angiotensin 1-9; ACE: angiotensin-converting enzyme; ACE2: Angiotensin-converting enzyme 2; AT1R: Angiotensin Receptor 1; AT2: Angiotensin Receptor 2; MASR: Mas receptors.

in HEK-293 overexpressing this enzyme and in Vero E6 cells endogenously expressing ACE2. The mechanism suggested for this $S$ protein effect is receptor-dependent endocytosis and the same has been hypothesized in susceptible cells challenged with SARS-CoV. Hajiasgharzadeh et al. (2019) showed that SARS-CoV also promotes TACE-dependent cleavage of ACE2 in plasmamembrane adding to ACE2 shedding and to a decrease of local ACE2 availability and activity. A demonstration, that S-proteindependent loss of ACE2 activity could facilitate the progression of lung inflammation, was given by experiments showing that the S-Fc fusion protein causes functional imbalance of the RAS mechanisms worsening the lung damage induced by acid aspiration in mice: this worsening effect is prevented with AT1 receptor antagonists (Su et al., 2010). The same mechanism has been suggested during COVID-19 and could critically contribute to the devastating progression of this disease.

\section{DOES THE CHOLINERGIC ANTI-INFLAMMATORY PATHWAY REGULATE PULMONARY RAS HINTS FROM THE COVID-19 PANDEMICS?}

The hypothesis that cholinergic mechanisms could modulate the RAS in the lung has been proposed to explain the effect of tobacco smoking on the risk of contracting COVID-19 (Changeux et al., 2020). A high prevalence of smokers among the COVID-19 patients with the most serious disease was reported at the beginning of the pandemic in China (Guan et al., 2020). Since then, several studies analyzed the relationship between tobacco smoking and the severity of COVID-19 infection with contradictory results. For instance, Vardavas and Nikitara (2020) showed that tobacco smoking increases the risk of a serious course of the disease; Lippi and Henry (2020) reported a nonsignificant trend for such association and Farsalinos et al. (2020) observed that in 13 studies from China the prevalence of smokers among patients with COVID was significantly lower than in general population. By examining 15 published studies, Alqahtani et al. (2020) found that the disease was much more serious in smokers than in non-smokers, although the prevalence of smokers and patients with Chronic obstructive pulmonary disease (COPD) was lower among patients with COVID-19. Another meta-analysis of data from 18 studies showed that smokers were statistically less likely to be hospitalized for serious COVID-19 (OR = 0.18, 95\% CI: 0.14-0.23, $p<0.01$ ) (GonzálezRubio et al., 2020). These data could suggest that tobacco smoking reduces the probability of contracting COVID-19 but worsens the prognosis of the disease when contracted. Whilst the effect of cigarette smoking on COVID-19 remains uncertain, experimental evidence supports the hypothesis that it increases 
ACE-2 activity as demonstrated in the peripheral blood of healthy volunteers (Kimura et al., 2019) and in isolated rat lungs (Bakhle et al., 1979). Moreover, it has been shown that the exposure to cigarette smoke increases the activity of both ACE and ACE2 activities in the lung in mice (Hung et al., 2016), and that the expression of ACE2 is higher in the small airways of human patients with COPD and in current smokers when compared with healthy subjects and former smokers (Alqahtani et al., 2020; Leung et al., 2020). Since tobacco smoke has many chemical components besides nicotine, it could affect ACE or ACE2 expression by multiple mechanisms, not necessarily limited to the nicotine-dependent stimulation of nAChR. For instance, it could induce tissue inflammation, which enhances the release of cytokines known to significantly increase ACE2 expression in the lung (Wösten-van Asperen et al., 2008), and selectively increases the number of the epithelial cells which express ACE2 including alveolar type I, globet and club cells (Smith et al., 2020). However, it is likely that nicotine by itself may exert a role in this process considering that it induces ACE2 upregulation in cultured human bronchial epithelial cells and this effect is blunted by the selective nAChR blocker, $\alpha$-bungarotoxin, and by anti- $\alpha 7$ siRNAs (Russo et al., 2020). Nicotine contained in smoke could be, therefore, acting as an activator of the cholinergic anti-inflammatory system in the lung, which could be beneficial in COVID-19 (Tizabi et al., 2020; Qin et al., 2021). Indeed, although cholinergic stimulation is expected to increase the density of the SARS-CoV2 receptor ACE2, the higher activity of this enzyme could reduce Ang II-induced proinflammatory status mainly by enhancing the levels of its functional antagonist Ang-(1-7) (Magalhaes et al., 2020). A further argument to suggest that nicotinic receptor stimulation could be beneficial in COVID-19 is that it could counteract the inhibitory effect of SARS-CoV2 on nicotinic receptors. As a matter of fact, it has been observed the $S$ protein of SARS CoV2 shows sequence analogies with the $\mathrm{nAChR}$ blocker $\alpha$-bungarotoxin (Kimura et al., 2019), and in silico studies showed that it can bind to $\mathrm{nAChR}$ and that several $\mathrm{nAChR}$ agonists including nicotine can effectively prevent this binding (Alexandris et al., 2020; Lagoumintzis et al., 2021). The inhibitory effects of SARS-CoV2 on $\mathrm{nAChR}$ are expected to imbalance the equilibrium between Ang II and Ang-(1-7) in favor of the former, hence promoting lung inflammation, whereas cholinergic stimulation could bring back to normal the Ang II/Ang-(1-7) balance. Under this respect, it is worth noting that beneficial

\section{REFERENCES}

Alexandris, N., Lagoumintzis, G., Chasapis, C. T., Leonidas, D. D., Papadopoulos, G. E., Tzartos, S. J., et al. (2020). Nicotinic cholinergic system and COVID19: In silico evaluation of nicotinic acetylcholine receptor agonists as potential therapeutic interventions. Toxicol. Rep. 8, 73-83. doi: 10.1016/j.toxrep.2020.12. 013

Alqahtani, J. S., Oyelade, T., Aldhahir, A. M., Alghamdi, S. M., Almehmadi, M., Alqahtani, A. S., et al. (2020). Prevalence, severity and mortality associated with COPD and smoking in patients with COVID-19: a rapid systematic review and meta-analysis. PLoS One 15:e0233147. doi: 10.1371/journal.pone.0233147

Bakhle, Y. S., Hartiala, J., Toivonen, H., and Uotila, P. (1979). Effects of cigarette smoke on the metabolism of vasoactive hormones in rat isolated effects of enhancing ACE-2 have been demonstrated in a single patient with severe COVID-19 (a trial is ongoing) who was given human recombinant soluble ACE2 with the double rationale of blocking SARS-CoV2 spike proteins and of lowering Ang II at the same time enhancing Ang-(1-7) (Zoufaly et al., 2020). Because of its well-known toxicity for the airways, cigarette smoke cannot be recommended to enhance cholinergic tone, but both pharmacological and non-pharmacological tools can be used to this aim. For instance, clinical trials are ongoing to evaluate the efficacy in COVID-19 patients of nicotine patches (the NICOVIDREA trial, NCT04598594), pyridostigmine bromide (the PISCO trial) (Fragoso-Saavedra et al., 2020) or vagal nerve stimulation (NCT04379037; Fudim et al., 2020; Staats et al., 2020). The results of these studies are eagerly expected as they could provide the clinical evidence, which is still missing (Wenzl, 2020), that cholinergic stimulation could be helpful in COVID-19 patients.

\section{CONCLUSIONS AND FUTURE PERSPECTIVES}

In conclusion, we have summarized the data suggesting that RAS and the cholinergic anti-inflammatory system may represent two major regulatory mechanisms of inflammation in the lung. We have reported that ACE2 acts as a receptor for SARS-CoV2 and the still controversial effect of tobacco smoking leading to a cholinergic hypothesis for COVID19. This hypothesis postulates that nicotine acting through nAChR modifies risk and prognosis of this disease by changing ACE2 levels (Figure 1). Besides the potential relevance for the pharmacological treatment of COVID-19, that remains to be established, the hypothesis that RAS and the cholinergic system may functionally interact certainly deserves further attention because of its potential implications for basic lung physiology and for the pathophysiology of pulmonary diseases.

\section{AUTHOR CONTRIBUTIONS}

MDM, MCa, and BG: conceptualization, supervision, and writing. MDM, MCh, and BDC: writing. MS, SD, AC, and BG: review and editing. All authors have read and agreed to the published version of the manuscript.

lungs. Br. J. Pharmacol. 65, 495-499. doi: 10.1111/j.1476-5381.1979.tb07 857.x

Benigni, A., Cassis, P., and Remuzzi, G. (2010). Angiotensin II revisited: new roles in inflammation, immunology and aging. EMBO Mol. Med. 2, 247-257. doi: $10.1002 / \mathrm{emmm} .201000080$

Benter, I. F., Yousif, M. H., Dhaunsi, G. S., Kaur, J., Chappell, M. C., and Diz, D. I. (2008). Angiotensin-(1-7) prevents activation of NADPH oxidase and renal vascular dysfunction in diabetic hypertensive rats. Am. J. Nephrol. 28, 25-33. doi: $10.1159 / 000108758$

Brégeon, F., Xeridat, F., Andreotti, N., Lepidi, H., Delpierre, S., Roch, A., et al. (2011). Activation of nicotinic cholinergic receptors prevents ventilatorinduced lung injury in rats. PLoS One 6:e22386. doi: 10.1371/journal.pone. 0022386 
Changeux, J. P., Amoura, Z., Reyd, F. A., and Miyarab, M. (2020). A nicotinic hypothesis for Covid-19 with preventive and therapeutic implications. C. R. Biol. 343, 1-7. doi: 10.5802/crbiol.8

Donoghue, M., Hsieh, F., Baronas, E., Godbout, K., Gosselin, M., Stagliano, N., et al. (2000). A novel angiotensin-converting enzyme-related carboxypeptidase (ACE2) converts angiotensin I to angiotensin 1-9. Circ. Res. 87, E1-E9. doi: 10.1161/01.res.87.5.e1

El-Hashim, A. Z., Renno, W. M., Raghupathy, R., Abduo, H. T., Akhtar, S., and Benter, I. F. (2012). Angiotensin-(1-7) inhibits allergic inflammation, via the MAS1 receptor, through suppression of ERK1/2- and NF- $\kappa$ B-dependent pathways. Br. J. Pharmacol. 166, 1964-1976. doi: 10.1111/j.1476-5381.2012. 01905.x

Farsalinos, K., Barbouni, A., and Niaura, R. (2020). Systematic review of the prevalence of current smoking among hospitalized COVID-19 patients in China: could nicotine be a therapeutic option? Intern. Emerg. Med. 16, 235-236. doi: 10.1007/s11739-020-02457-2

Fox, B., Bull, T. B., and Guz, A. (1980). Innervation of alveolar walls in the human lung: an electron microscopic study. J. Anat. 131, 683-692.

Fragoso-Saavedra, S., Iruegas-Nunez, D. A., Quintero-Villegas, A., GarcíaGonzález, H. B., Nuñez, I., Carbajal-Morelos, S. L., et al. (2020). A parallelgroup, multicenter randomized, double-blinded, placebo-controlled, phase $2 / 3$, clinical trial to test the efficacy of pyridostigmine bromide at low doses to reduce mortality or invasive mechanical ventilation in adults with severe SARS-CoV-2 infection: the Pyridostigmine in severe Covid-19 (PISCO) trial protocol. BMC Infect. Dis. 20:765. doi: 10.1186/s12879-020-05485-7

Fudim, M., Qadri, Y. J., Ghadimi, K., MacLeod, D. B., Molinger, J., Piccini, J. P., et al. (2020). Implications for neuromodulation therapy to control inflammation and related organ dysfunction in COVID-19. J. Cardiovasc. Transl. Res. 13, 894-899. doi: 10.1007/s12265-020-10031-6

Galvão, I., Rago, F., Moreira, I. Z., and Teixeira, M. M. (2019). “Angiotensin1-7 and Inflammation," in Angiotensin-(1-7), ed. R. Santos (Cham: Springer), 201-218. doi: 10.1007/978-3-030-22696-1_13

González-Rubio, J., Navarro-López, C., López-Nájera, E., López-Nájera, A., Jiménez-Díaz, L., Navarro-López, J. D., et al. (2020). A systematic review and meta-analysis of hospitalised current smokers and COVID-19. Int. J. Environ. Res. Public Health 17:7394. doi: 10.3390/ijerph17207394

Guan, W. J., Ni, Z. Y., Hu, Y., Liang, W. H., Ou, C. Q., He, J. X., et al. (2020). Clinical characteristics of coronavirus disease 2019 in China. N. Engl. J. Med. 382, 1708-1720. doi: 10.1056/NEJMoa2002032

Hajiasgharzadeh, K., Sadigh-Eteghad, S., Mansoori, B., Mokhtarzadeh, A., Shanehbandi, D., Doustvandi, M. A., et al. (2019). Alpha7 nicotinic acetylcholine receptors in lung inflammation and carcinogenesis: friends or foes? J. Cell. Physiol. 234, 14666-14679. doi: 10.1002/jcp.28220

Hoffmann, M., Kleine-Weber, H., Schroeder, S., Krüger, N., Herrler, T., Erichsen, S., et al. (2020). SARS-CoV-2 cell entry depends on ACE2 and TMPRSS2 and is blocked by a clinically proven protease inhibitor. Cell 181, 271-280.e8. doi: 10.1016/j.cell.2020.02.052

Hollenhorst, M. I., Jurastow, I., Nandigama, R., Appenzeller, S., Li, L., Vogel, J., et al. (2020). Tracheal brush cells release acetylcholine in response to bitter tastants for paracrine and autocrine signaling. FASEB J. 34, 316-332. doi: 10.1096/fj. 201901314RR

Hollenhorst, M. I., Lips, K. S., Wolff, M., Wess, J., Gerbig, S., and Takats, Z. (2012). Luminal cholinergic signalling in airway lining fluid: a novel mechanism for activating chloride secretion via $\mathrm{Ca}^{2+}$-dependent $\mathrm{Cl}^{-}$and $\mathrm{K}^{+}$channels. Br. J. Pharmacol. 166, 1388-1402. doi: 10.1111/j.1476-5381.2012.01883.x

Hung, Y. H., Hsieh, W. Y., Hsieh, J. S., Liu, F. C., Tsai, C. H., Lu, L. C., et al. (2016). Alternative roles of STAT3 and MAPK signaling pathways in the MMPs activation and progression of lung injury induced by cigarette smoke exposure in ACE2 knockout mice. Int. J. Biol. Sci. 12, 454-465. doi: 10.7150/ijbs.13379

Khan, A., Benthin, C., Zeno, B., Albertson, T. E., Boyd, J., Christie, J. D., et al. (2017). A pilot clinical trial of recombinant human angiotensin-converting enzyme 2 in acute respiratory distress syndrome. Crit. Care 21:234. doi: 10. 1186/s13054-017-1823-x

Khani, M. A., SalehiRad, M., Darbeheshti, S., and Motaghinejad, M. (2020). Survival of COVID-19 patients requires precise immune regulation: the hypothetical immunoprotective role of nicotinic agonists. Med. Hypotheses 143:109871. doi: 10.1016/j.mehy.2020.109871
Kimura, K., Inaba, Y., Watanabe, H., Matsukawa, T., Matsumoto, M., and Inoue, H. (2019). Nicotinic alpha-7 acetylcholine receptor deficiency exacerbates hepatic inflammation and fibrosis in a mouse model of non-alcoholic steatohepatitis. J. Diabetes Investig. 10, 659-666. doi: 10.1111/jdi.12964

Krasteva, G., Canning, B. J., Hartmann, P., Veres, T. Z., Papadakis, T., Mühlfeld, C., et al. (2011). Cholinergic chemosensory cells in the trachea regulate breathing. Proc. Natl. Acad. Sci. U.S.A. 108, 9478-9483. doi: 10.1073/pnas.1019418108

Kuba, K., Imai, Y., Rao, S., Gao, H., Guo, F., Guan, B., et al. (2005). A crucial role of angiotensin converting enzyme 2 (ACE2) in SARS coronavirus-induced lung injury. Nat. Med. 11, 875-879. doi: 10.1038/nm1267

Kumar, P., Scholze, P., Fronius, M., Krasteva-Christ, G., and Hollenhorst, M. I. (2020). Nicotine stimulates ion transport via metabotropic $\beta 4$ subunit containing nicotinic ACh receptors. Br. J. Pharmacol. 177, 5595-5608. doi: 10.1111/bph.15270

Kummer, W., Lips, K. S., and Pfeil, U. (2008). The epithelial cholinergic system of the airways. Histochem. Cell Biol. 130, 219-234.

Lagoumintzis, G., Chasapis, C. T., Alexandris, N., Kouretas, D., Tzartos, S., Eliopoulos, E., et al. (2021). Nicotinic cholinergic system and COVID-19: in silico identification of interactions between $\alpha 7$ nicotinic acetylcholine receptor and the cryptic epitopes of SARS-Co-V and SARS-CoV-2 Spike glycoproteins. Food Chem. Toxicol. 149:112009. doi: 10.1016/j.fct.2021.11 2009

Leung, J. M., Yang, C. X., Tam, A., Shaipanich, T., Hackett, T. L., and Singhera, G. K. (2020). ACE-2 expression in the small airway epithelia of smokers and COPD patients: implications for COVID-19. Eur. Respir. J. 55:2000688. doi: 10.1183/13993003.00688-2020

Lippi, G., and Henry, B. M. (2020). Active smoking is not associated with severity of coronavirus disease 2019 (COVID-19). Eur. J. Intern. Med. 75, 107-108. doi: 10.1016/j.ejim.2020.03.014

MacKenzie, A. (2011). Endothelium-derived vasoactive agents, AT1 receptors and inflammation. Pharmacol. Ther. 131, 187-203. doi: 10.1016/j.pharmthera.2010. 11.001

Magalhães, G. S., Campagnole-Santos, M. J., and da Glória Rodrigues-Machado, M. (2019). "Lung," in Angiotensin-(1-7), ed. R. Santos (Cham: Springer), $131-152$.

Magalhaes, G. S., Rodrigues-Machado, M. D. G., Motta-Santos, D., CampagnoleSantos, M. J., and Santos, R. A. S. (2020). Activation of Ang-(1-7)/Mas receptor is a possible strategy to treat coronavirus (SARS-CoV-2) infection. Front. Physiol. 11:730. doi: 10.3389/fphys.2020.00730

Marshall, R. P., McAnulty, R. J., and Laurent, G. J. (2000). Angiotensin II is mitogenic for human lung fibroblasts via activation of the type 1 receptor. Am. J. Respir. Crit. Care Med. 161, 1999-2004. doi: 10.1164/ajrccm.161.6.9907004

Perniss, A., Latza, A., Bosevaa, I., Papadakisa, T., Damesb, C., Meisel, C., et al. (2020). Acute nicotine administration stimulates ciliary activity via $\alpha 3 \beta 4$ $\mathrm{nAChR}$ in the mouse trachea. Int. Immunopharmacol. 84:106496. doi: 10.1016/ j.intimp.2020.106496

Qin, Z., Xiang, K., Su, D. F., Sun, Y., and Liu, X. (2021). Activation of the cholinergic anti-inflammatory pathway as a novel therapeutic strategy for COVID-19. Front. Immunol. 11:595342. doi: 10.3389/fimmu.2020.595342

Russo, P., Bonassi, S., Giacconi, R., Malavolta, M., Tomino, C., and Maggi, F. (2020). COVID-19 and smoking: is nicotine the hidden link? Eur. Respir. J. 55:2001116. doi: 10.1183/13993003.01116-2020

Silva, A. C. S. E., and Teixeira, M. M. (2016). ACE inhibition, ACE2 and angiotensin-(1-7) axis in kidney and cardiac inflammation and fibrosis. Pharmacol. Res. 107, 154-162. doi: 10.1016/j.phrs.2016.03.018

Smith, J. C., Sausville, E. L., Girish, V., Yuan, M. L., Vasudevan, A., John, K. M., et al. (2020). Cigarette smoke exposure and inflammatory signaling increase the expression of the SARS-CoV-2 receptor ACE2 in the respiratory tract. Dev. Cell 53, 514-529.e3. doi: 10.1016/j.devcel.2020.05.012

Staats, P., Giannakopoulos, G., Blake, J., Liebler, E., and Levy, R. M. (2020). The use of non-invasive vagus nerve stimulation to treat respiratory symptoms associated with COVID-19: a theoretical hypothesis and early clinical experience. Neuromodulation 23, 784-788. doi: 10.1111/ner.13172

Su, X., Matthay, M. A., and Malik, A. B. (2010). Requisite role of the cholinergic alpha7 nicotinic acetylcholine receptor pathway in suppressing Gram-negative sepsis-induced acute lung inflammatory injury. J. Immunol. 184, 401-410. doi: 10.4049/jimmunol.0901808 
Tipnis, S. R., Hooper, N. M., Hyde, R., Karran, E., Christie, G., and Turner, A. J. (2000). A human homolog of angiotensin-converting enzyme. Cloning and functional expression as a captopril-insensitive carboxypeptidase. J. Biol. Chem. 275, 33238-33243. doi: 10.1074/jbc.M002615200

Tizabi, Y., Getachew, B., Copeland, R. L., and Aschner, M. (2020). Nicotine and the nicotinic cholinergic system in COVID-19. FEBS J. 287, 3656-3663. doi: $10.1111 /$ febs. 15521

Treml, B., Neu, N., Kleinsasser, A., Gritsch, C., Finsterwalder, T., Geiger, R., et al. (2010). Recombinant angiotensin-converting enzyme 2 improves pulmonary blood flow and oxygenation in lipopolysaccharide induced lung injury in piglets. Crit. Care Med. 38, 596-601. doi: 10.1097/CCM.0b013e3181c0 3009

Vardavas, C. I., and Nikitara, K. (2020). COVID-19 and smoking: a systematic review of the evidence. Tob. Induc. Dis. 18:20. doi: 10.18332/tid/119324

Wang, R., Zagariya, A., Ibarra-Sunga, O., Gidea, C., Ang, E., Deshmukh, S., et al. (1999). Angiotensin II induces apoptosis in human and rat alveolar epithelial cells. Am. J. Physiol. 276, L885-L889. doi: 10.1152/ajplung.1999.276.5.L885

Wang, Y., Pereira, E. F., Maus, A. D., Ostlie, N. S., Navaneetham, D., Lei, S., et al. (2001). Human bronchial epithelial and endothelial cells express alpha7 nicotinic acetylcholine receptors. Mol. Pharmacol. 60, 1201-1209. doi: 10.1124/ mol.60.6.1201

Wang, Y., Zhu, Y., Zhu, Y., Lu, Z., and Xu, F. (2017). Regulation of the angiotensin II-p22phox-reactive oxygen species signaling pathway, apoptosis and 8-oxoguanine-DNA glycosylase 1 retrieval in hyperoxia-induced lung injury and fibrosis in rats. Exp. Ther. Med. 13, 3397-3407. doi: 10.3892/etm. 2017.4429

Wenzl, T. (2020). Smoking and COVID-19 - A Review of Studies which Motivated Unexpected Health Claims, EUR 30373 EN. Luxembourg: Publications Office of the European Union.
World Health Organization (WHO) (2020). Coronavirus Disease (COVID19) Pandemic. Avaliable online at: https://www.who.int/emergencies/diseases/ novel-coronavirus-2019 (accessed June 10, 2020)

Wösten-van Asperen, R. M., Lutter, R., Haitsma, J. J., Merkus, M. P., Van Woensel, J. B., Van Der Loos, C. M., et al. (2008). ACE mediates ventilator-induced lung injury in rats via angiotensin II but not bradykinin. Eur. Respir. J. 31, 363-371. doi: 10.1183/09031936.00060207

Yamada, M., and Ichinose, M. (2018). The cholinergic anti-inflammatory pathway: an innovative treatment strategy for respiratory diseases and their comorbidities. Curr. Opin. Pharmacol. 40, 18-25. doi: 10.1016/j.coph.2017. 12.003

Zhang, H., and Sun, G. Y. (2005). LPS induces permeability injury in lung microvascular endothelium via AT(1) receptor. Arch. Biochem. Biophys. 441, 75-83. doi: 10.1016/j.abb.2005.06.022

Zoufaly, A., Poglitsch, M., Aberle, J. H., Hoepler, W., Seitz, T., Traugott, M., et al. (2020). Human recombinant soluble ACE2 in severe COVID-19. Lancet Respir. Med. 8, 1154-1158. doi: 10.1016/S2213-2600(20)30418-5

Conflict of Interest: The authors declare that the research was conducted in the absence of any commercial or financial relationships that could be construed as a potential conflict of interest.

Copyright (c) 2021 Di Maro, Cataldi, Santillo, Chiurazzi, Damiano, De Conno, Colantuoni and Guida. This is an open-access article distributed under the terms of the Creative Commons Attribution License (CC BY). The use, distribution or reproduction in other forums is permitted, provided the original author(s) and the copyright owner(s) are credited and that the original publication in this journal is cited, in accordance with accepted academic practice. No use, distribution or reproduction is permitted which does not comply with these terms. 